Objective The aim of the study was to detect the prevalence of obesity in teenagers, the presence of the complications of the disease and alimentation pattern.

Material and method We had studied 162 teenagers from "Gr. Antipa" collegium, Brasov. the protocol of the study consist in clinical examination, body mass index calculoation (BMI), and a questionair regarding alimentation and phisical exercises.

Results In our study cohort 102 subjects (62.96\%) had BMI on the 95 th percentiles for agen and sex, $18(11.11 \%)$ on the 97 th percentiles and $7(4.3 \%)$ on the 99th percentiles. $152(93.82 \%)$ children had had alimentation disorders(sweets, soda, chips, fastfood almost dayly and fresh fruits ocasionaly). 110 children $(67.90 \%)$ had a sedentary life (TV, PC, no physical exercises). The main complications detected were hypertension (27\%), hypercholesterolemia (50\%), diabetes mellitus type $2(8 \%)$ and secundary amenohreea (6\%).

Conclusions Overweight and obesity is a reality in teenager cohort. More, there are present complications of the disease even in childhood. The main cause of the obesity is "life style" which include alimentation disorders and poor physical exercises. All the efforts should be made in education of the adolescents for the prevention of the obesity because an obese child shall became an obese young adult with degenerative cardiovascular pathology.

\section{USING BIA TO EVALUATE WEIGHT STATUS COMPARED TO BMI IN IRAINIAN CHILDREN WHIT AUTISM SPECTRUM DISORDERS}

doi:10.1136/archdischild-2012-302724.1453

${ }^{1} \mathrm{H}$ Salehi, 'S Shahmohammadlu, ${ }^{2 M}$ Mahmoudi, 'K Djafarian. 'Department of Nutrition and Biochemistry; ${ }^{2}$ Department of Biostatisticsand Epidemiology, School of Public Health, Tehran University of Medical Sciences, Tehran, Iran

Background and Aims Body composition is more important than body weight and body fat is a good guideline used to evaluate health Status better than sole weight. The aim of this study was to compare BIA and BMI to evaluate body weight status in autistic children and adolescents males in Iran.

Methods Eighty-one children and adolescents aged $7-13$ years old were selected randomly from 4 autism-specific schools in Tehran in 2011. Body composition of children was measured using BIA.

Results The findings revealed that on the basis of body mass index(BMI), $41.9 \%$ of children were normal weight $\left(5^{\text {th }}<\mathrm{BMI}<85^{\text {th }}\right)$, but $16 \%$ were overweight $\left(85^{\text {th }}<\mathrm{BMI}<95^{\text {th }}\right), 27.1 \%$ obese $\left(\mathrm{BMI}>95^{\text {th }}\right)$ and $14.8 \%$ underweight $\left(\mathrm{BMI}<5^{\mathrm{th}}\right)$, respectively. Based on percent body fat $(\mathrm{PBF}), 76.5 \%$ of children were normal body fat $\left(5^{\text {th }}<\mathrm{PBF}\right.$ $\left.<85^{\text {th }}\right), 3.7 \%$ of children were under the 5 th percentile, $12.3 \%$ were overweight $\left(85^{\text {th }}<\mathrm{PBF}<95^{\mathrm{th}}\right)$, and $7.4 \%$ were above the 95 percentiles.

Conclusions Although using BMI is simple and easy method for evaluating body weight status, measuring body fat by BIA is another alternative which give better picture of body composition in different health settings.

\section{IMPACT OF A CHAM JAM INTERVENTION ON PHYSICAL FITNESS IN ELEMENTARY SCHOOL STUDENTS}

doi:10.1136/archdischild-2012-302724.1454

M Reznik, PO Ozuah. Pediatrics, Children's Hospital at Montefiore, Albert Einstein College of Medicine, Bronx, NY, USA

Background and Aims CHAM JAM, a classroom-based physical activity intervention, has been effective in increasing physical activity levels in elementary school students. The objective if this study was to determine the impact of CHAM JAM on physical fitness.
Design and methods A cluster-randomized wait-listed controlled study at 6 Bronx, NY elementary schools. Two schools received CHAM JAM. We randomly selected a subset of 3rd grade students from intervention and control schools to measure physical fitness. Physical fitness testing included heart rate (HR) response to submaximal exercise assessed with a modified step test at baseline and 3 -months post-intervention. Students stepped up and down on step of calculated height for 3 minutes at a step cadence of 22 ascents/ minute. We measured HR pre-exercise, at peak exercise, and at 1-, 2-, and 3-min recovery period. Hierarchical linear models were used to evaluate differences in mean HR between and within the groups. Models controlled for gender, age, and BMI.

Results A total of 378 students participated (intervention, 176; control, 202). Between-group difference in HR change revealed that intervention group achieved significantly greater decrease in HR than control group.

Abstract 1454 Table 1 Adjusted differences in HR between groups

\begin{tabular}{lccc}
\hline Outcome & Difference Estimate & SE & p value \\
\hline HR pre-exercise & -4.89 & 1.25 & $<0.0001$ \\
HR peak & -3.67 & 1.76 & $<0.0375$ \\
HR 1 min & -4.16 & 1.48 & $<0.0052$ \\
HR 2 min & -4.95 & 1.32 & $<0.0002$ \\
HR 3 min & -5.21 & 1.29 & $<0.0001$ \\
\hline
\end{tabular}

Conclusions The CHAM JAM intervention improved physical fitness.

\section{PREVENTION OF CORONARY HEART DISEASE RISK FACTORS IN CHILDREN - THE ROLE OF HEALTHY NUTRITION}

doi:10.1136/archdischild-2012-302724.1455

${ }^{1} \mathrm{M}$ Kelmendi, ${ }^{2} \mathrm{R}$ Bejiqi, ${ }^{2} \mathrm{R}$ Retkoceri, ${ }^{2} \mathrm{~A}$ Batalli-Kepuska, ${ }^{2} \mathrm{H}$ Bejiqi. 'Cardiology; 2University Children's Hospital, Prishtina, Kosovo

Coronary heart disease (CHD) is the commonest cause of morbidity and mortality worldwide. Our country, as a developing one is facing also with many, "new fashioned" diseases, which are becoming epidemic in developed world, such as: obesity, diabetes mellitus, hypercholesterolemia, stress and unhealthy diet.

Objective The aim of this study is

1. To present food patterns in schoolchildren in our region and

2. To stress the role of healthy nutrition in the prevention of CHD.

Methods Two hundred schoolchildren, aged from 7-15 years, examined at University Children's Hospital, are included in this study. They are selected at random and mostly suffer from respiratory infections, throat infections, rheumatic fever, etc. Except history, physical examination, laboratory and anthropometric measures, an questionnaire regarding to food habits was filled by all patients.

Results Of 200 examined children, there were 150 (75.0\%)with normal weight (<97 percentile), $36(18.0 \%)$ underweight $(<3$ percentile) and $14(7.0 \%)$ overweight ore obese ( $>97$ percentile). There were $10(5.0 \%)$ children with dislypidaemia and $6(3.0 \%)$ with hypertension. The questionnaires analysis revealed many unhealthy habits: $75.0 \%$ prefer processed and fast food, $85.0 \%$ sweetened fruit drinks and soda. On the other hand, the consumption of healthy food, such as: milk, honey, fruits, whole grains, vegetables, functional foods, fish etc is very low.

Conclusion This paper underlines the link between food and health, especially in children; they, as a very vulnerable segment of population are often "victims" of food industry which offer them: high content of salt, sugar, trans fat. 
DIFFERENCES OF INSULIN GENE GENOTYPES AND INSULIN LEVELS IN OBESE CHILDREN

doi:10.1136/archdischild-2012-302724.1456

'A Solntsava, ${ }^{2} E$ Aksionava, 'L Viazava, ${ }^{2} \mathrm{~N}$ Danilenko, 'A Sukalo. 'Belarusian State Medical University; ${ }^{2}$ Institute of Genetics and Cytology, National Academy of Science, Republic of Belarus, Minsk, Belarus

Aim To compare gender and pubertal insulinemia levels and frequencies of Insulin gene (INSG) genotype rates in lean (control (C)) and obese $(O)$ children.

Methods $578 \mathrm{O}$ and $204 \mathrm{C}$ children were investigated (divided into groups: prepubertal $O\left(1^{\text {st }}-\mathrm{o}\right) \mathrm{m} / \mathrm{f} \mathrm{n}=178 / 117$ and $\mathrm{C}\left(1^{\text {st }}-\mathrm{c}\right) \mathrm{n}=51 / 46$, early pubertal $\left(2^{\text {nd }}-0\right) n=67 / 41$ and $\left(2^{\text {nd }}-c\right) n=16 / 17$, late pubertal $\left(3^{\text {rd }}-\right.$ o) $n=88 / 87$ and $\left.\left(3^{\text {rd }}-c\right) n=14 / 60\right)$. $129 O$ girls and $144 O$ boys and 104 lean girls and 55 lean boys were genotyped in INSG (A-23HphIT polymorphism). Serum insulin was detected by radioimmunoassay technique. Statistical analysis was performed using SPSS 16.0 $(\mathrm{p}=0.05)$.

Results Insulin ranges were significantly higher in $O$ children than in $\mathrm{Cl}$ regardless of pubertal stage and sex: $\mathrm{p}=0,0001$ between the $1^{\text {st }}-o$ and $1^{\text {st }}-c, p=0,001$ in the $2^{\text {nd }}$ groups and $p=0,0001$ in the $3^{\text {rd }}$ groups respectively. Correlations between insulinemia and BMI $(\mathrm{r}=0.4, \mathrm{p}=0,0001)$ were revealed. There were gender differences (hisquare 6.56; $p<0.05$ ) between genotypes rates occurrence in $O$ children: $51.9 \%$ girls and $61.8 \%$ boys had AA-genotype, $13.2 \%$ girls and $4.9 \%$ boys - TT, versus to C children: AA-genotype was found in $61.5 \%$ girls and $56.4 \%$ boys, TT-genotype - in 3.8\% girls and $5.5 \%$ boys ( $p>0.05$ ). Insulin level was higher in $O$ children with AA homozygote genotype in compared with TT-genotype $(p=0,003)$. There were no changes of insulin values in control group irrespective of the genotype polymorphisms.

Conclusion A-23HphIT INS genotypes in girls with adiposity were significant differ from normal children irrespective of gender. Insulin level in obese children depends on A-23HphIT INS polymorphisms.

\section{ASSESSMENT OF KNOWLEDGE, ATTITUDE AND PRACTICE OF HEALTH PROFESSIONALS REGARDING BREAST FEEDING IN KING FAHAD ARMED FORCES HOSPITAL}

doi:10.1136/archdischild-2012-302724.1457

'M Abou Al-Seoud, 1,2MA Azzam, 'I Hassan, 1,2D El-Metwally. 'Pediatrics, King Fahad Armed Forces Hospital, Jeddah, Saudi Arabia; ${ }^{2}$ Pediatrics and Neonatology, Suez Canal University (FOMSCU), Ismailia, Egypt

Background and Aims It has been recognized that exclusive breast-feeding rates in our community are suboptimal. To determine if one of the reasons is insufficient counselling, we aimed to assess knowledge, attitude and practice of health professionals in our community.

Methods This was a prospective study performed in King Fahad Armed Forces Hospital during the yearly conference. We designed a questionnaire divided into three sections of multiple choice questions, the first assessing knowledge of basic facts related to breastfeeding, with the second and third assessing attitude and practice. A total of 322 questionnaires were filled in by physicians and nurses from various departments, midwives and health educators. Means and differences between occupations were calculated, and statistical analysis was performed using SPSS version 17.0.

Results Mean knowledge score was $70 \% \pm 10.1 \%$. Differences between occupations was highly significant ( $p$ value $<0.001$ ) with the highest scores in NICU physicians. Despite this variation, attitude and practice did not differ significantly between groups and positive answers were found in $92 \%$ and $61.4 \%$ respectively. Surprisingly, although $88 \%$ felt they were doing their best, only $42 \%$ gave options for working mothers, just below $50 \%$ tried to persuade nursing mothers regarding exclusive breast feeding, and a mere $36 \%$ counselled mothers on possible obstacles and how to overcome them.

Conclusions Despite generally high knowledge scores in our study population, as well as positive attitudes, actual practices need to be improved. Further studies to assess barriers to optimal counselling practices need to be performed.

\section{PHYSICAL ACTIVITY IN PRIMARY SCHOOL CHILDEN OF TEHRAN CITY}

doi:10.1136/archdischild-2012-302724.1458

${ }^{1} \mathrm{~K}$ Djafarian, 'A Zamani, 'A Saber Gharamaleki, ${ }^{2} \mathrm{M}$ Hosseini. 'Department of Nutrition and Biochemistry; ${ }^{2}$ Department of Biostatistics and Epidemiology, School of Public Health, Tehran University of Medical Sciences, Tehran, Iran

Background and Aims It is clear that measuring physical activity (PA) in children is a major challenge and Accelerometers are useful instruments for this reason. The aims of this study were to measure PA pattern of student by accelerometer and to evaluate differences by gender and age.

Methods The sample for present study comprised 270 children (boys $n=119$ and girls $n=151$ ), aged 6 to 9 years old. The GT3X activity monitor was used as an objective measure of daily PA. Each student was scheduled to wear the accelerometer during the week of monitoring.

Results The mean overall activity was higher in boys than in girls, but this difference was significant only on weekdays $(\mathrm{P}<0.05)$. Overall PA was significantly correlated with age both in whole week $(\mathrm{P}<0.01)$ and weekends $(\mathrm{P}<0.001)$

Conclusion Our findings are important for a better understanding of PA pattern in students of Tehran city, which is essential for education and health promotion. The results show that boys are more active than girls.

\section{SOCIO-CULTURAL FACTORS RELATED TO MALNUTRITION IN COMMUNITIES OF CENTRAL INDIA}

doi:10.1136/archdischild-2012-302724.1459

'R Dwivedi, ${ }^{2} \mathrm{~A}$ Agrawal. 'Pediatrics, Gandhi Medical College; ${ }^{2}$ Pediatrics, Gandhi Medical College/Barkatullah University, Bhopal, India

Background New WHO child growth standards confirmed that children born anywhere in the world have same growth potential, given the optimum start. Growth is influenced more by nutrition, feeding practices, environment, and healthcare than genetics or ethnicity.

Objective To assess the impact of various socio-cultural factors on nutritional status of children.

Setting Randomly selected Anganwadis, 5 each from 3 randomly selected ICDS (Integrated Child Development Scheme) blocks from total 7 ICDS blocks of Bhopal district.

Patients 400 children between 6 months to 3 years registered at selected Anganwadis.

Methods Data collection using structured questionnaire including information on demography, socioeconomic status, feeding practices, knowledge and beliefs regarding childhood nutrition and utilization of different government-led services. This was supplemented by detailed physical examination and anthropometric assessment.

Results Out of 400 children, 123 (30.75\%) were moderately malnourished while $30(7.5 \%)$ were severely malnourished with slight female predominance (53.4 and $54.6 \%$ respectively). Low birth weight, higher birth order $(\geq 4)$, delayed initiation and early interruption of breast-feeding, mixed feeding, bottle-feeding, delayed initiation of complementary feeding; irregular Anganwadi visits and illiteracy of parents were significantly associated with malnutrition. 